\title{
Water Dynamics Combined with a Supply of NPK Solutes and Urea in a 3-Layer Soil Profile under Drip Irrigation
}

\author{
Siguibnoma Kévin Landry Ouédraogo*, Marcel Bawindsom Kébré, François Zougmoré \\ Laboratoire de Matériaux et Environnement, UFR/ST, Université Joseph KI-ZERBO, Ouagadougou, Burkina Faso \\ Email: *siguibnoma@gmail.com
}

How to cite this paper: Ouédraogo, S.K.L., Kébré, M.B. and Zougmoré, F. (2021) Water Dynamics Combined with a Supply of NPK Solutes and Urea in a 3-Layer Soil Profile under Drip Irrigation. Agricultural Sciences, 12, 1321-1341.

https://doi.org/10.4236/as.2021.1211085

Received: October 14, 2021

Accepted: November 27, 2021

Published: November 30, 2021

Copyright $\odot 2021$ by author(s) and Scientific Research Publishing Inc. This work is licensed under the Creative Commons Attribution International License (CC BY 4.0).

http://creativecommons.org/licenses/by/4.0/

\begin{abstract}
The intensive and inappropriate use of water, fertilizers and phytosanitary products is sources of water and soil pollution. It is thus necessary to improve the management of irrigation water in order to optimize its use and productivity, especially in regions where water resources are becoming increasingly scarce. The water flow and non-reactive solutes' transport simulation under drip irrigation were carried out in a 3-layered soil profile distributed from top to bottom i.e., sandy, sandy-silty, silty-sandy-clay. The aim of this study was thus, to provide a good practice of water management associated with solutes' application, in order to retain as much solute as possible in the root zone, which will increase the residence time of the solutes. Three treatments of water flux corresponding to $100 \% E T_{\circ}, 75 \% E T_{\circ} 50 \% E T_{\circ}$ combined with 100 $\mathrm{mmol} / \mathrm{L} / \mathrm{m}^{2}$ of NPK and $246 \mathrm{mmol} / \mathrm{L} / \mathrm{m}^{2}$ of urea applicable in two doses, were carried out over a period of 110 days corresponding to the duration of the cropping cycle for the intermediate variety of maize. The $100 \% E T_{c}$ and $75 \% E T_{c}$ treatments cause more loss of water and solutes, because of the sandy texture of the soil. However, a $50 \% E T_{c}$ water flux would reduce more water loss through drainage, and solutes' loss due to leaching beyond the root zone, which would increase the residence time of solutes in the soil profile. Application tests of the NPK solute on different days before the $15^{\text {th }}$ day after sowing were also carried out according to the technical itinerary for maize production in Burkina Faso, in order to find a favorable day for application of the solute. For the different dates of solute's application, there was more loss of the solute as we approach the $15^{\text {th }}$ day after sowing. To limit this loss and increase the residence time of the NPK solute, one could apply the solute without first supplying water, the day before and the day after the date of solute' injection. Or, one could amend the soil with organic matter to improve its retention capacity of water, and the solutes' residence time in the soil.
\end{abstract}




\section{Keywords}

Drip Irrigation, Hydrus 1D, Solute and Water Management, Residence Time

\section{Introduction}

The search for a continuous increase in agricultural productivity, the standardization of technology, and the intensification of the production led in the 1980s to negative environmental impacts on agro-ecosystems, such as erosion, reduction of biodiversity, water and soil pollution. Intensive and inappropriate use of water, fertilizers and phytosanitary products are sources of water and soil pollution [1] [2] [3]. This water and soil pollution by pesticides has become a major health problem [4]. It is thus necessary to improve the management of irrigation water in order to optimize its use and productivity, especially in regions where water resources are becoming increasingly scarce [5]. Irrigated agriculture, the main objective of which is to improve irrigation water management and increase productivity, will be used. Irrigation techniques can indeed meet the challenge of reasonable management of water resources and fertilizers. Among the existing irrigation methods, drip irrigation systems offer enormous potential as compared to other systems. Indeed, they significantly reduce evaporation, apply water and fertilizers directly to the root zone and greatly reduce loss. Due to these advantages, drip irrigation has become the most accepted method of irrigation/fertigation in order to improve the efficient use of water and nitrogen, as well as minimize nitrate leaching [6]. However, a potential problem associated with drip irrigation is the deep percolation and leaching of nutrients beyond the root zone [7] [8] [9] [10] [11], which could be a source of soil and groundwater pollution. In Burkina Faso, where the lack of water continues to increase each year, the adoption of drip irrigation as an alternative by producers is slowly taking place, despite the enormous benefits that this irrigation system could bring to producers. In order to better support producers, studies therefore need to be carried out, especially on how to manage water and fertilizers for the proper planning of irrigated agriculture with drip irrigation. The main objective of this study was thus, to propose good practices for the application of water associated with fertilizers (NPK; urea) in order to retain as many fertilizers as possible in the root zone as long as possible, for the production of corn under drip irrigation. Doing so, could maximize the residence time of solutes, which could also increase the solute's uptake by the plant. More specifically, our objective was to: 1) study the dynamics of NPK (14-23-14) and urea (46-0-0) in the soil; 2) predict the risks of leaching according to the dose and the time of application; 3 ) provide a good management of the soil and a good use of the crop. Proper design of drip systems requires knowledge of the wetting front distribution around the dripper. Although several studies have been carried out to investigate the dy- 
namics of water in soil under drip irrigation (e.g. [12] [13] [14]), it is still difficult to design management strategies for the optimization of the quantity of irrigation water, its frequency, and the location of drippers, in order to achieve the highest water use efficiency [15]. Simulation models have been valuable research tools for studies taking into account the interactive and complex processes of water flow and solutes' transport in the soil, and also the effects of management practices on yields as well as the environment [16] [17]. These simulations can be used to assess the efficiency of irrigation systems over several seasons, and advise producers if this requires improvement in several aspects of the functioning of the irrigation systems [18]. Numerical simulation as a tool to optimize the management of irrigation practices is a fast and an inexpensive approach; it has been used a lot over the past ten years. Among the numerical models used, the Hydrus model, thanks to its flexibility in taking into account different boundary conditions, and the uptake of water and nutrients by the roots of the plant, and an easy-to-access user interface, was much successfully used in several studies (e.g. [7] [10] [15] [19]-[24]) to simulate the movement of water under drip irrigation. In this study, we used Hydrus $1 \mathrm{D}$ to simulate water flow and non-reactive solutes' transport in one dimension (vertical axis), in a 3-layer soil, and we did not take into account water and solutes' root uptake.

\section{Methods and Materials}

\subsection{Process}

The studied scenario consisted of an application of urea (46-0-0) and NPK (14-23-14) for the production of maize (intermediate variety 95 - 110 days) through a simulated drip irrigation with the Hydrus 1D software. In order to assess deep drainage, and solutes' leaching according to the day of application, the water flux and the solutes' concentration, neither the crop nor the water and solutes' uptake by roots were considered in this simulation. The two solutes applied were considered as tracers, therefore having no interaction with the environment. Also, they were provided in liquid form with the irrigation water. The water supplies were first made at $100 \% E T_{c}$. This, in order to observe possible loss of water and solutes if the irrigation were scheduled daily, and then, to proceed with an irrigation planning when the water is considered as a limiting factor, or to reduce loss. The quantities of solutes supplied were in accordance with those recommended for maize production in Burkina Faso, according to J. Sanou (2004). The scenarios were simulated according to the initial and boundary conditions in order to get closer to the reality

\subsection{Plot of Land Meshing}

We considered a plot of land with an area of $500 \mathrm{~m}^{2}(25 \mathrm{~m} \times 20 \mathrm{~m})$ irrigated by surface drip irrigation system, with a flow rate of $2 \mathrm{l} / \mathrm{h}$ (the most frequently used flow under in our tropics). The crop used was maize (intermediate variety) with 
a production cycle of 110 days. We used the recommendations of the Ministry of Agriculture in terms of inter-crop and inter-row spacing of $40 \mathrm{~cm} \times 80 \mathrm{~cm}$. For the area to be irrigated, there will be 31 lines of pipes and 50 drippers per line, i.e., a total of 1550 drippers (pockets) are given in Figure 1.

\subsection{Fertilizers Dosage}

For semi-intensive agriculture, the quantities of urea (46-0-0) and NPK (14-23-14) to be used for maize production are respectively $150 \mathrm{~kg} / \mathrm{ha}$ and $200 \mathrm{~kg} / \mathrm{ha}$ (J. Sanou, 2004). Table 1 gives the quantities of fertilizer and their date of application. For a small village irrigation $\left(500 \mathrm{~m}^{2}\right)$, we determined the concentration of urea and NPK to apply according to the area:

\section{- NPK concentration}

From sowing date until to the 15th day after sowing, the NPK dose to use is $200 \mathrm{~kg} / \mathrm{ha}$, i.e., $0.02 \mathrm{~kg} / \mathrm{m}^{2}$ or $20 \mathrm{~g} / \mathrm{m}^{2}$. For NPK (14-23-14) or $14 \%$ of $\mathrm{N}_{2}$, we will have $2.8 \mathrm{~g} / \mathrm{m}^{2}$. The concentration being the number of moles per volume quantity, we considered a liter $(1 \mathrm{~L})$ of solution. The molar concentration would therefore be $0.1 \mathrm{~mol} / \mathrm{L} / \mathrm{m}^{2}$ or $100 \mathrm{mmol} / \mathrm{L} / \mathrm{m}^{2}$. This concentration value was considered as input data for the NPK simulation.

\section{- Urea concentration}

In total, we used $150 \mathrm{~kg} / \mathrm{ha}$ of urea (46-0-0) in two applications:

\section{On the $30^{\text {th }}$ day after sowing}

We used $100 \mathrm{~kg} / \mathrm{ha}$ of urea (46-0-0) or $46 \mathrm{~kg} / \mathrm{ha}$ or $4.6 \mathrm{~g} / \mathrm{m}^{2}$ of urea. The concentration being the number of moles per quantity of volume, we considered a liter $(1 \mathrm{~L})$ of solution. The molar concentration would therefore be $0.164 \mathrm{~mol} / \mathrm{L} / \mathrm{m}^{2}$ or $164 \mathrm{mmol} / \mathrm{L} / \mathrm{m}^{2}$.

\section{On the $45^{\text {th }}$ day after sowing}

The quantity envisioned is $50 \mathrm{~kg} / \mathrm{ha}$ of urea $(46-0-0)$ or $23 \mathrm{~kg} / \mathrm{ha}$ of urea, which

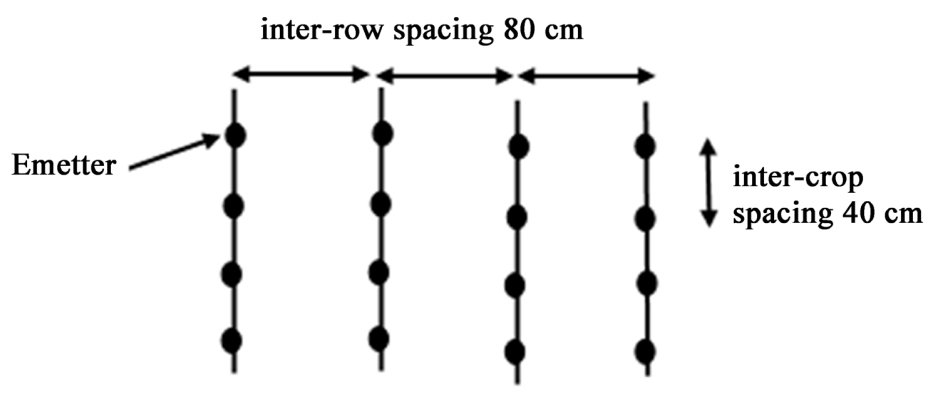

Figure 1. Row and crop spacing.

Table 1. Urea and NPK doses used for semi-intensive production [25].

\begin{tabular}{cccc}
\hline Fertilizer & Base & Application date & Quantity \\
\hline NPK & $14-23-14$ & Sowing up to $15^{\text {th }}$ day after sowing & $200 \mathrm{~kg} / \mathrm{ha}$ \\
Urea 1 & $46-0-0$ & At the $30^{\text {th }}$ day after sowing & $100 \mathrm{~kg} / \mathrm{ha}$ \\
Urea 2 & $46-0-0$ & At the $45^{\text {th }}$ day after sowing & $50 \mathrm{~kg} / \mathrm{ha}$ \\
\hline
\end{tabular}


is equivalent to $2.3 \mathrm{~g} / \mathrm{m}^{2}$. By going to the concentration, we obtained 0.082 $\mathrm{mol} / \mathrm{L} / \mathrm{m}^{2}$ or even $82 \mathrm{mmol} / \mathrm{L} / \mathrm{m}^{2}$.

\subsection{Field of Study}

The study area Figure 2 was a one meter deep soil profile, made up of 3 layers and initially dry. These three layers are distributed from top to bottom in a sandy layer, sandy-silt, and sandy-clay silt. The initial water contents in these different layers were equal to the residual water contents. In this study domain, we placed observation nodes $\mathrm{N} 1, \mathrm{~N} 2, \mathrm{~N} 3, \mathrm{~N} 4$, and $\mathrm{N} 5$ respectively on the soil surface of $0 \mathrm{~cm}, 20 \mathrm{~cm}, 50 \mathrm{~cm}, 75 \mathrm{~cm}$ and $100 \mathrm{~cm}$ in depth.

The soil properties used for the simulation were determined experimentally thanks to a complete characterization of the physical, morphological and hydrodynamic properties in [26]. We presented the physical parameters of the 3 different layers necessary for the simulation in Table 2. The parameters alpha $\alpha$ and $n$ were derived from particle size distribution and bulk density in [26] with the ROSETTA pedotransfer function. And the other parameters $\theta_{s}$ and $K_{s}$ were determined experimentally by [26]. At the beginning of the simulation, the soil did not contain any solute, the irrigation water also did not. The ground surface was subject to an atmospheric boundary condition with meteorological values that were those of Burkina Faso, obtained from the National Meteorological Agency. The surface of the domain was also subjected to variable fluxes of water and solutes in order to take into account the inputs of water and fertilizer. The bottom boundary of the domain was subject to free drainage, and the side walls, to zero flux of water and solutes. The various meteorological data are shown in Table 3. Water supplies were made according to the plant's water

Water and solutes variable flux, and atmospheric conditions

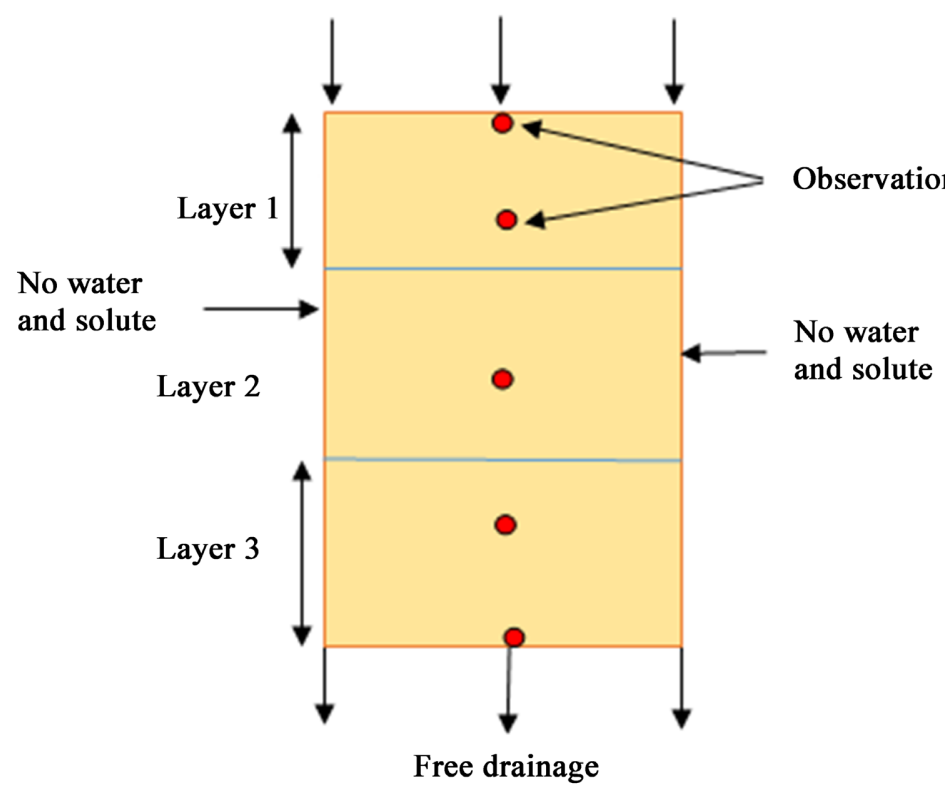

Figure 2. Domain flow and boundary conditions as well as observations nodes. 
Table 2. Soil hydraulic properties.

\begin{tabular}{ccccccc}
\hline Parameters & $\theta_{r}$ & $\theta_{s}$ & $\alpha$ & $n$ & $K_{s}$ & $l$ \\
\hline Layer 1 & 0 & 0.3655 & 0.0377 & 2.4559 & 268.932 & 0.5 \\
Layer 2 & 0 & 0.37 & 0.0378 & 1.9234 & 28.27 & 0.5 \\
Layer 3 & 0.0057 & 0.396 & 0.0259 & 1.2733 & 35.251 & 0.5 \\
Units & $\mathrm{m} . \mathrm{m}^{-3}$ & $\mathrm{~m} . \mathrm{m}^{-3}$ & $\mathrm{~cm}^{-1}$ & - & $\mathrm{cm} . \mathrm{jr}^{-1}$ & - \\
\hline
\end{tabular}

Table 3. Meteorological parameters used for simulation.

\begin{tabular}{cccccccc}
\hline Time (day) & $E T_{0}$ & Radiation & $T_{\min }$ & $T_{\max }$ & Humidity & Wind & Sunshine \\
\hline $1-21$ & 6.8377 & 16.4071 & 19.9190 & 35.2428 & 25.3809 & 236.16 & 7.3714 \\
$22-42$ & 6.7290 & 18.0452 & 22.5857 & 38.0285 & 29.2619 & 196.251 & 8.34761 \\
$43-63$ & 8.1371 & 19.5380 & 24.6952 & 40.1857 & 26.5238 & 242.742 & 8.3190 \\
$64-110$ & 6.4298 & 18.5943 & 27.6695 & 39.1630 & 45.3586 & 222.949 & 7.7 \\
Units & $\mathrm{mm} /$ day & $\mathrm{MJ} / \mathrm{m}^{2} /$ day & ${ }^{\circ} \mathrm{C}$ & ${ }^{\circ} \mathrm{C}$ & $\%$ & $\mathrm{Km} /$ day & $\mathrm{hr}$ \\
\hline
\end{tabular}

Table 4. Water flux and solutes' concentration applied at the top of the domain.

\begin{tabular}{cccc}
\hline Time (day) & Flux top & Concentration of solute 1 & Concentration of solute 2 \\
\hline $1-21$ & 0.266 & $100 \mathrm{NPK}$ & \\
$22-42$ & 0.631 & & 164 Urea 1 \\
$43-63$ & 0.722 & 82 Urea 2 \\
$64-110$ & 0.459 & $\mathrm{mmol} / \mathrm{L} / \mathrm{m}^{2}$ & \\
Units & $\mathrm{cm} /$ day & & $\mathrm{mmol} / \mathrm{L} / \mathrm{m}^{2}$ \\
\hline
\end{tabular}

requirements, which were determined by the FAO method Equation (1).

$$
E T_{c}=E T_{0} \times K_{c}
$$

In which, $E T_{c}$ is the crop water evapotranspiration (mm/day), $E T_{0}$ the potential evapotranspiration ( $\mathrm{mm} /$ day); and $K_{c}$ the dimensionless maize crop coefficient depending on plant growth. In Table 4 we summarize the different inputs of water and solutes during the simulation period.

\subsection{Water Flow and Solutes' Transport Modeling}

The Hydrus 1D software [27] was used for the one-dimensional numerical simulation of water, and solutes' transport in the soil column. The water flow in a variably saturated medium is described by the Richards equation:

$$
\frac{\partial \theta}{\partial t}=\frac{\partial}{\partial z}\left[K(h) \frac{\partial h}{\partial z}+K(h)\right]
$$

where $\mathrm{z}$ is the vertical coordinate $(\mathrm{cm})$; and $h$ the soil water pressure head $(\mathrm{cm}) ; t$ the time (day); $K$ the hydraulic conductivity function $\left(\mathrm{cm} \cdot \mathrm{day}^{-1}\right) ; \theta$ the volume- 
tric water content $\left(\mathrm{cm}^{3} \cdot \mathrm{cm}^{-3}\right)$.

The hydraulic conductivity function is given by the van-Genuchten (1980) Mualem (1976) relationnships in Equation (3) [28].

$$
\begin{gathered}
S_{e}(h)=\frac{\theta(h)-\theta_{r}}{\theta_{\text {sat }}-\theta_{r}}=\left[1+(\alpha h)^{n}\right]^{-m} \\
K(h)=K_{s} S_{e}^{l}\left[1-\left(1-S_{e}^{1 / m}\right)^{m}\right]^{2}
\end{gathered}
$$

In which $S_{e}$ is the effective saturation, $\theta_{r}$ and $\theta_{s}$ respectively denote the residual and saturated water contents $\left(\mathrm{cm}^{3} \cdot \mathrm{cm}^{-3}\right) . K_{s}$ is the saturated hydraulic conductivity $\left(\mathrm{cm} \cdot \mathrm{day}^{-1}\right), \alpha\left(\mathrm{cm}^{-1}\right)$ and $n(-)$ are empirical shape parameters, $l$ is a pore connectivity/tortuosity parameter $(-)$.

The solutes' transport is represented by a convective-dispersive transport equation. Convection accounts for the macroscopic transport of solutes, which accompany the fluid. Diffusion accounts for both molecular diffusion and hydrodynamic dispersion. No nitrogen transformation was considered in the simulation process. Thus, the adsorption, precipitation/dissolution, volatilization of nitrogen were neglected. The equation governing the transport of non-reactive solutes in a homogeneous porous medium is written as:

$$
\frac{\partial(\theta c)}{\partial t}=\frac{\partial}{\partial z}\left(\theta D \frac{\partial c}{\partial z}\right)-\frac{\partial q c}{\partial z}
$$

where $c$ is the concentration of the species in the liquid phase $\left(\mathrm{M} \cdot \mathrm{L}^{-3}\right) ; D$ the hydrodynamic dispersion coefficient of the chemical species $\left(\mathrm{L}^{2} \cdot \mathrm{T}^{-1}\right)$, and $q$ the water flow $\left(\mathrm{L} \cdot \mathrm{T}^{-1}\right)$.

\section{Results and Discussion}

We presented the results of the simulation for a 110 days duration (duration of the crop cycle) below. The first results obtained were in conformity with the technical route recommended for maize production in Burkina Faso using of fertilizers. Figure 3 and Figure 4 respectively gave the potential pressure head and the water content, versus time at the various observation nodes. These two Figure 3 and Figure 4 show how the water is distributed through the soil, from the surface (node N1: $0 \mathrm{~cm}$ ) to the bottom of the domain (node N5: $-100 \mathrm{~cm}$ ). Figure 4 and Figure 5 respectively show the concentration of NPK and urea versus time at the different observation nodes. Through Figure 5 and Figure 6, we saw how the solutes infiltrate and then, spread throughout the soil from the application date. By analyzing Figure 3, we noticed that, with a water flux of $0.266 \mathrm{~cm} /$ day applied to the surface (node N1) during the first 21 days, the water reached the layers $\mathrm{N} 2, \mathrm{~N} 3, \mathrm{~N} 4$, and N5 respectively 1 day, 7 day, 12 day, 17 day after application. Beyond the $40^{\text {th }}$ day of irrigation, the pressure potential in nodes N4 and N5 was greater than that of nodes N1, N2, N3, which means that the quantity of water leaving the deep layers was greater than that coming from the upper layers. Beyond the $65^{\text {th }}$ day, the curves of the various observation 


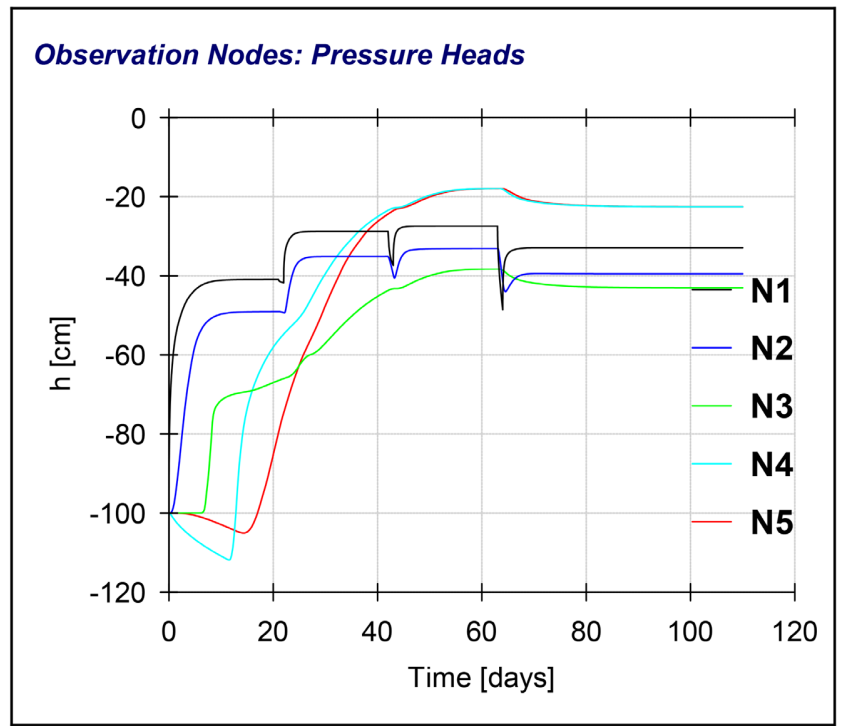

Figure 3. Pressure Head versus time at selected observation points $(\mathrm{N} 1: 0 \mathrm{~cm}$; N2: -20 cm; N3: $-50 \mathrm{~cm}$; N4: $-75 \mathrm{~cm}$; N5: $-100 \mathrm{~cm}$ ).

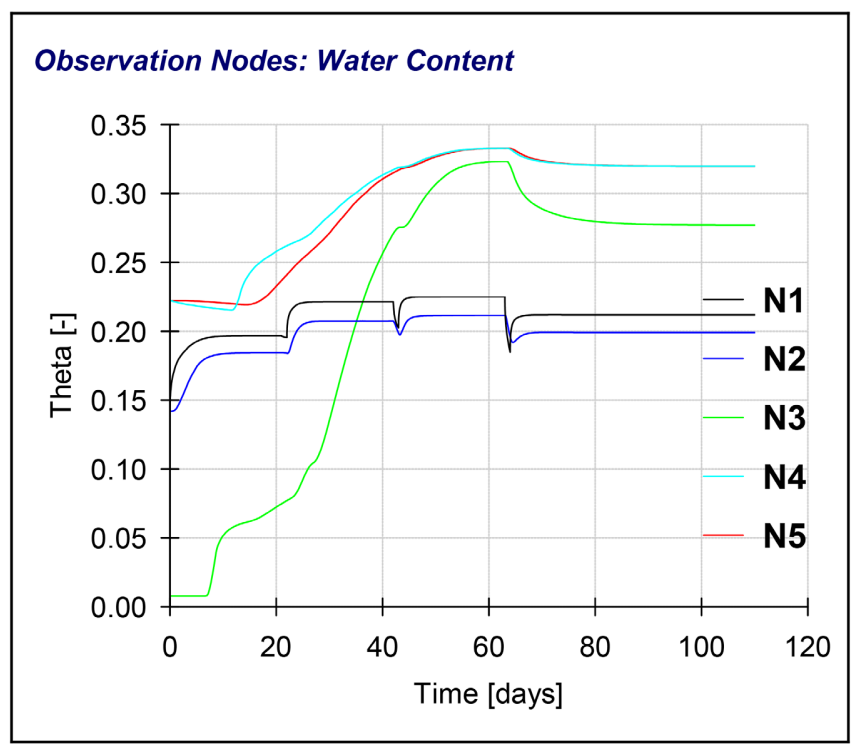

Figure 4. Water Content versus time at selected observation points $(\mathrm{N} 1: 0 \mathrm{~cm}$; N2: -20 cm; N3: $-50 \mathrm{~cm}$; N4: $-75 \mathrm{~cm}$; N5: $-100 \mathrm{~cm}$ ).

nodes were almost parallel, until the end day of simulation. We therefore, saw the water flux reach an equilibrium state in the entire soil profile. We also noticed that, the water flux leaving the soil profile at node N5 was greater than the flux of water infiltrating the surface at node N1, which means a loss of water from the $40^{\text {th }}$ day until the end day of the simulation ( $110^{\text {th }}$ day). Figure 4 showing the water content versus time at the different observation nodes, looks like Figure 3, which confirmed the previous results. The observation of nodes N1, $\mathrm{N} 3$ and N5 in Figure 3, clearly shows that the water stock above $50 \mathrm{~cm}$ was greater than that in the first $50 \mathrm{~cm}$ of the ground. 


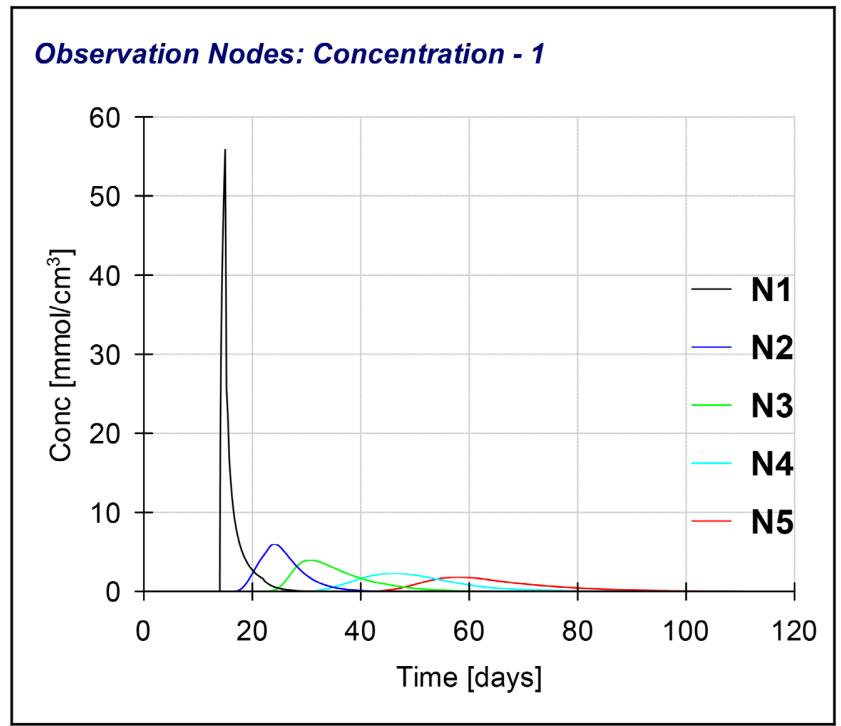

Figure 5. Solute (NPK) concentration versus time at selected observation points (N1: 0 cm; N2: $-20 \mathrm{~cm}$; N3: $-50 \mathrm{~cm}$; N4: $-75 \mathrm{~cm}$; N5: $-100 \mathrm{~cm}$ ).

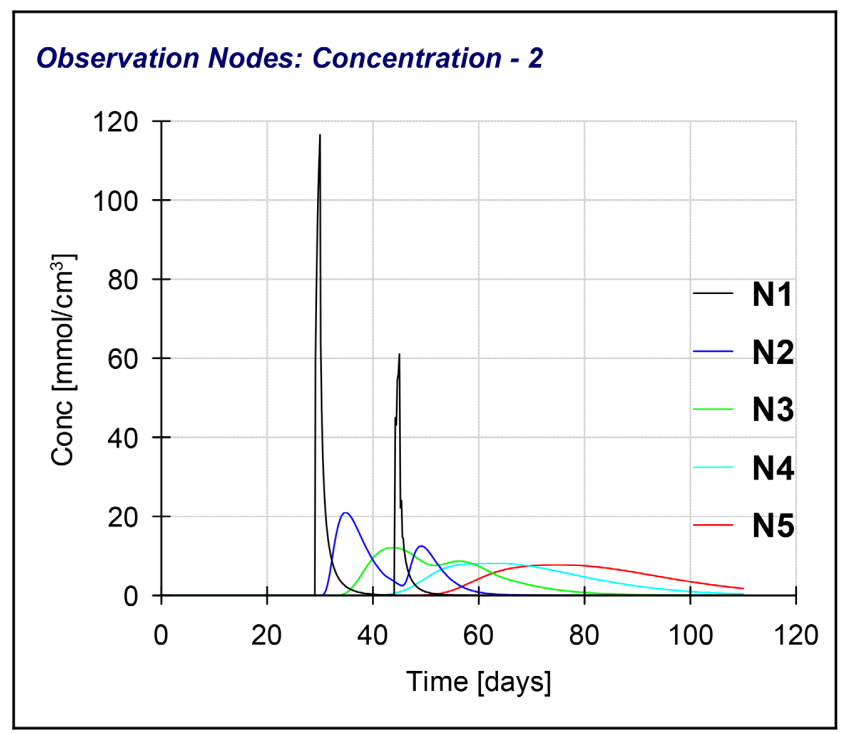

Figure 6. Solute (Urea) concentration versus time at selected ob-servation points (N1: 0 cm; N2: $-20 \mathrm{~cm}$; N3: $-50 \mathrm{~cm}$; N4: $-75 \mathrm{~cm}$; N5: $-100 \mathrm{~cm}$ ).

The NPK (concentration 1) was injected on the $15^{\text {th }}$ day. As the water seeps into the soil, it carries the solutes with it through the entire soil profile. The concentration of solute available on the surface of the soil gradually decreased until it was completely leached on the $30^{\text {th }}$ day. The solute, respectively reaches a depth of $20 \mathrm{~cm}$ (node N2) and $50 \mathrm{~cm}$ (node N3) on the $17^{\text {th }}$ day and $22^{\text {nd }}$ day after sowing, which means respectively, 2 days and 7 days after application of the NPK. The NPK continues its distribution and reaches the bottom of the domain (node N5: $100 \mathrm{~cm}$ ) on the $47^{\text {th }}$ day. As the water continues to seep into the soil, all of the solute concentration applied to the soil surface will be leached, and 
thus, returning the soil profile to its initial state of zero concentration. What occurred after the $75^{\text {th }}$ day, with the solute concentration in all layers being zero, the soil was completely leached. The solute concentration in the different layers of the soil remained low, a peak of around $6 \mathrm{mmol} / \mathrm{cm}^{3}$ was reached at a depth of $20 \mathrm{~cm}$ on the $25^{\text {th }}$ day. The concentration beyond $20 \mathrm{~cm}$ of depth remained lower than the observed peak. In Figure 6, two supplying of urea (concentration 2) were made on the $30^{\text {th }}$ and $45^{\text {th }}$ day after sowing, which is observable at node N1: $0 \mathrm{~cm}$. Because of the dispersion, this concentration of solute progressively reaches respectively nodes N3: $-50 \mathrm{~cm}$ and N4: $-75 \mathrm{~cm}$ on the $32^{\text {nd }}$ and $40^{\text {th }}$ day. The solute concentration not being zero at node N5 at the end of the simulation, we deduced that the solute remains in the soil at the end of the simulation. These analyzes show that, a large part of the water and solutes used, was lost through drainage and leaching beyond the root zone, especially in the early stages of the crop development. As for the volume of water and the quantity of solute stored in the soil, the quantity (NPK in particular) would be unusable by the crops, because they was stored beyond a certain depth $(-60 \mathrm{~cm})$ of the non-colonized soil by the roots at the first stage of the crop development. We performed different simulations in order to limit the volume of water, and a certain high concentration of solutes in the first half of the soil, where the root density is higher for the first phase of corn growth between 1 and 21 days. As the root volume is still growing until the maturity of the maize during which time, urea was applied in two doses, the urea could still be absorbed by the roots even beyond $60 \mathrm{~cm}$ depth. It was therefore necessary to optimize the application of NPK, as it can be applied from seedling to the $15^{\text {th }}$ day after sowing, a period included in the initial phase of growth, for which root development is not important.. In order to reduce the water loss by drainage as well as NPK loss, we carried out water supplies at $100 \% E T_{\circ}, 75 \% E T_{\circ}$ and at $50 \% E T_{c}$ with new treatments for NPK's inputs and thus found a favorable day in which there would be less loss and longer residence time, as compared to other days of application.

\section{1. $100 \% E T_{c}$ and NPK Applied Either on the $1^{\text {st }}, 5^{\text {th }}, 1^{\text {th }}$ or $15^{\text {th }}$ Day after Sowing}

When the NPK was applied the $1^{\text {st }}$ day after sowing Figure 7, we can see through the various observation nodes that the solute concentration was watched out from the surface (node N1) of the soil on the $25^{\text {th }}$ day after application, and the maximum concentration was $60 \mathrm{mmol} / \mathrm{cm}^{3}$. The solution continues its distribution and reached the $\mathrm{N} 2$ node 2 days after application, with a maximum (6 $\mathrm{mmol} / \mathrm{cm}^{3}$ ) reached on the $20^{\text {th }}$ day. The solute left the $20 \mathrm{~cm}$ depth on the $39^{\text {th }}$ day. After 9 days, the solute then reached a depth of $50 \mathrm{~cm}$ (node N3) for which, peak concentration was $5 \mathrm{mmol} / \mathrm{cm}^{3}$, and beyond the $60^{\text {th }}$ day, it leached over the depth of $50 \mathrm{~cm}$. The $\mathrm{N} 4$ node was reached on the $15^{\text {th }}$ day with a peak concentration of $3.75 \mathrm{mmol} / \mathrm{cm}^{3}$. The solute left the $\mathrm{N} 4$ horizon on the $75^{\text {th }}$ day.

For an NPK treatment on the $5^{\text {th }}$ day after sowing Figure 8 , all the solute 


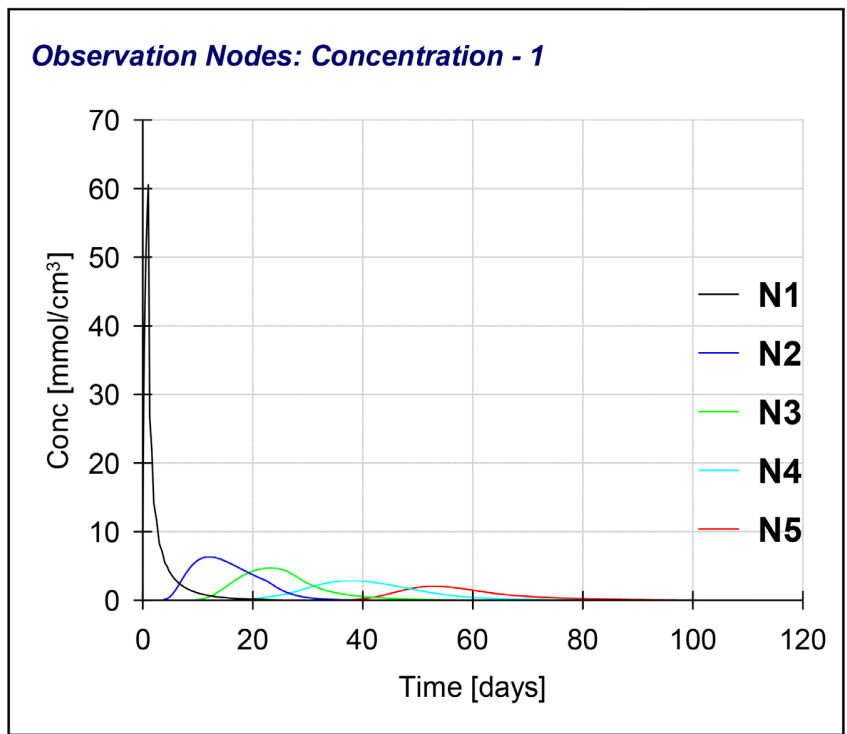

Figure 7. Solute (NPK) concentration versus time at selected observation points (N1: 0 $\mathrm{cm} ; \mathrm{N} 2:-20 \mathrm{~cm}$; N3: $-50 \mathrm{~cm}$; N : $-75 \mathrm{~cm} ; \mathrm{N} 5:-100 \mathrm{~cm}$ ) applied at day 1 .

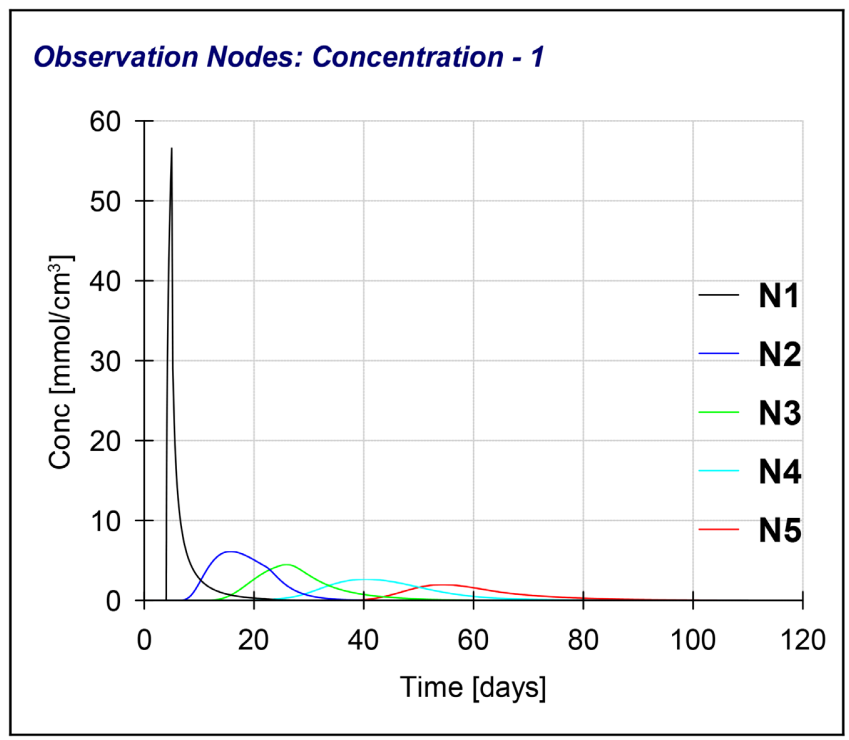

Figure 8. Solute (NPK) concentration versus time at selected observation points (N1: 0 $\mathrm{cm} ; \mathrm{N} 2:-20 \mathrm{~cm}$; N3: $-50 \mathrm{~cm}$; N4: $-75 \mathrm{~cm} ; \mathrm{N} 5:-100 \mathrm{~cm}$ ) applied at day 5 .

disappeared from the soil surface on the $28^{\text {th }}$ day. The maximum concentration observed at this level was $56 \mathrm{mmol} / \mathrm{cm}^{3}$. The solute front reached $\mathrm{N} 2$ on the $7^{\text {th }}$ day with a maximum concentration of $7.75 \mathrm{mmol} / \mathrm{cm}^{3}$ on the $15^{\text {th }}$ day. The solute was leached to the depth of $20 \mathrm{~cm}$ on the $40^{\text {th }}$ day.

The water continuing its infiltration carried the solute with it to node N3 on day 12 , and leaves the depth on the $60^{\text {th }}$ day. On the $20^{\text {th }}$ day, the solute reached node $\mathrm{N} 4$ and leaves this depth on the $75^{\text {th }}$ day.

Figure 9 (NPK applied on the $10^{\text {th }}$ day after sowing) on the soil surface, the solute was leached before the $30^{\text {th }}$ day. The solute continues to progress until it 
reached node $\mathrm{N} 2$ on the $12^{\text {th }}$ day with a maximum concentration of $6 \mathrm{mmol} / \mathrm{cm}^{3}$; the solute leaves this region of the soil on the $43^{\text {rd }}$ day. Node N3 was reached on the $17^{\text {th }}$ day, and the solute was leached from this horizon on the $65^{\text {th }}$ day. 10 days after reaching node N3, the solute then reaches node N4 in order to flow past $\mathrm{N} 4$ by the $90^{\text {th }}$ day.

The application of NPK on the $15^{\text {th }}$ day after sowing Figure 10 shows a disappearance of the solute from the soil surface $(\mathrm{N} 1)$ on the $32^{\text {nd }}$ day. The solute front continues to distribute and reached $\mathrm{N} 2$ on the $17^{\text {th }}$ day and then vanished on the $46^{\text {th }}$ day. Nodes N3 and N4 were reached after the $22^{\text {nd }}$ and $30^{\text {th }}$ day

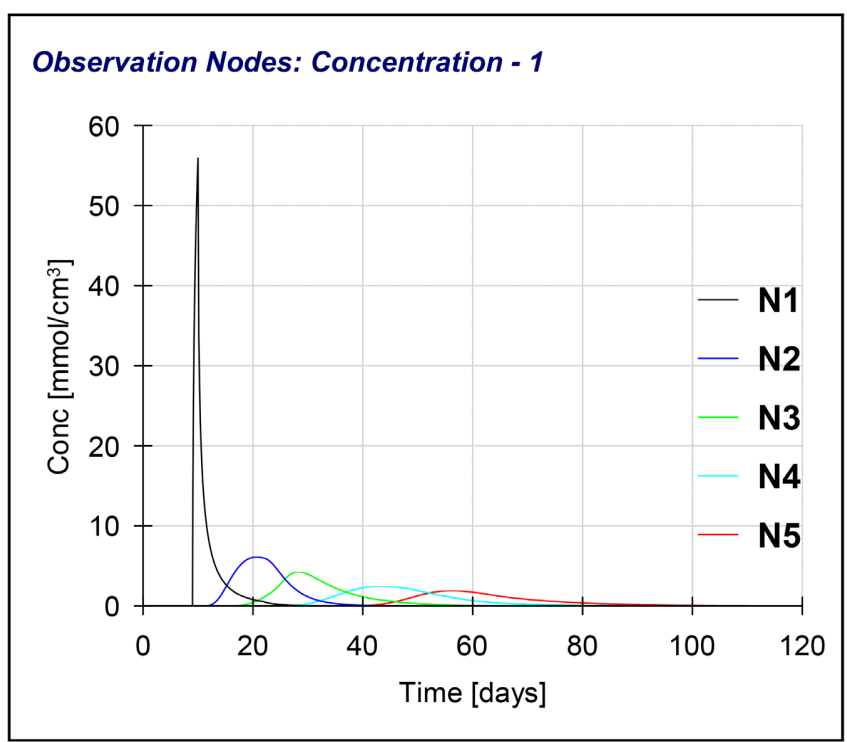

Figure 9. Solute (NPK) concentration versus time at selected observation points (N1: 0 $\mathrm{cm} ; \mathrm{N} 2:-20 \mathrm{~cm} ; \mathrm{N} 3:-50 \mathrm{~cm} ; \mathrm{N} 4:-75 \mathrm{~cm} ; \mathrm{N} 5:-100 \mathrm{~cm}$ ) applied at day 10.

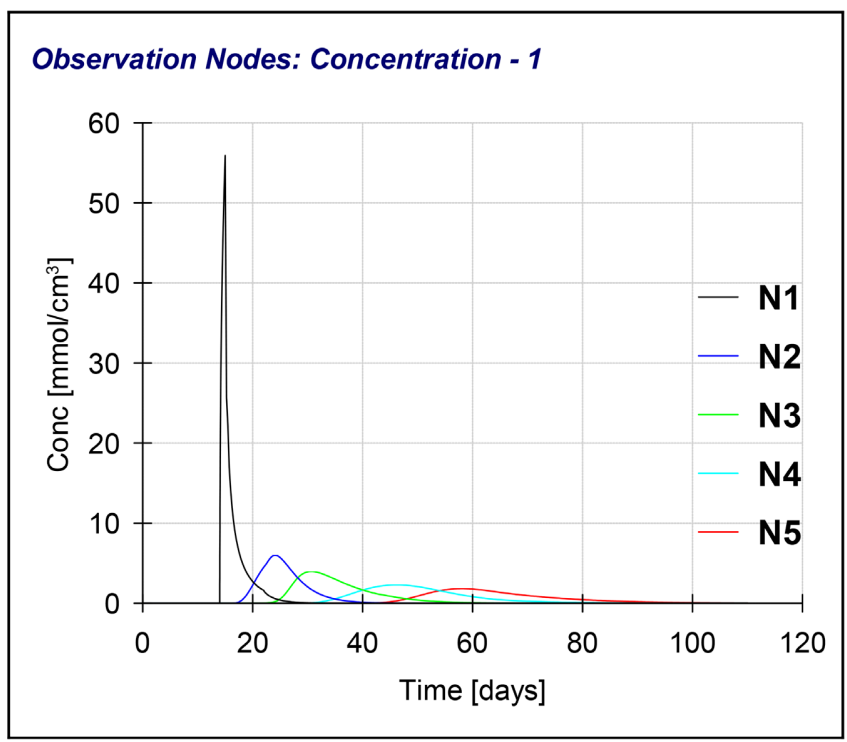

Figure 10. Solute (NPK) concentration versus time at selected observation points (N1: 0 cm; N2: $-20 \mathrm{~cm} ; \mathrm{N} 3:-50 \mathrm{~cm} ; \mathrm{N} 4:-75 \mathrm{~cm} ; \mathrm{N} 5:-100 \mathrm{~cm}$ ) applied at day 15. 
respectively. The solute front leaves the N3 and N4 horizon on the $67^{\text {th }}$ and the $95^{\text {th }}$ day, respectively.

Note that for $100 \% E T_{\mathcal{\circ}}$ regardless of the period of application of NPK to the soil surface, the residence time of NPK on the soil surface did not exceed 25 days, which was the longest stay in the surface when the solute was applied on the $1^{\text {st }}$ day after sowing. For each date of application, the solution reached nodes $\mathrm{N} 2$ and N3 respectively, 2 days and 7 days after application. On the other hand, the concentration in the various observation nodes decreases as one approaches the $15^{\text {th }}$ day in order to carry out the solute's intake. All solute in the soil was lost on the $110^{\text {th }}$ day after sowing, regardless of when the solute was supplied.

\subsection{Water Flux $75 \% E T_{c}$ and NPK Applied Either on the $1^{\text {st }}, 5^{\text {th }}$, $10^{\text {th }}$ or $15^{\text {th }}$ Day after Sowing}

For a treatment of $75 \% E T_{c}$ as water supply, we considered the same treatments as above for the solutes' supply. By observing the pressure head curve in the soil at different observation nodes, we noticed that the quantity of water stored in the soil and lost at node N5 was less as compared to the quantity stored and lost for a treatment of $100 \% E T_{c} .75 \% E T_{c}$ therefore reduced water loss through drainage. To save space, we did not present the figure giving the pressure head potential.

Supply of solute on the $1^{\text {st }}$ day of simulation Figure 11: the concentration reached a peak of $55 \mathrm{mmol} / \mathrm{cm}^{3}$, the solute made approximately 30 days on the soil surface (Node N1). On the $4^{\text {th }}$ day, the solute has reached node $\mathrm{N} 2$ with a peak concentration of $5 \mathrm{mmol} / \mathrm{cm}^{3}$, the solute has left this horizon on the $46^{\text {th }}$ day after application. At 11 days of the application, the solute has reached node $\mathrm{N} 3$ with a peak of $4 \mathrm{mmol} / \mathrm{cm}^{3}$, and left this depth on the $72^{\text {nd }}$ day. Node N4 was reached on the $20^{\text {th }}$ day and cancels itself out on the $106^{\text {th }}$ day. All the concentration

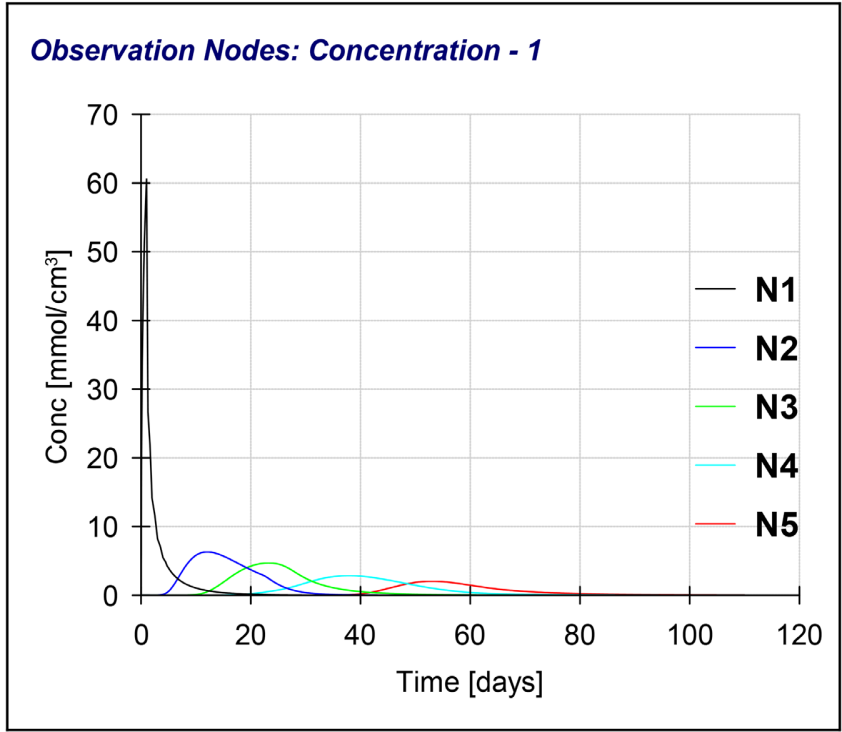

Figure 11. Solute (NPK) concentration versus time at selected observation points (N1: 0 $\mathrm{cm}$; N2: $-20 \mathrm{~cm}$; N3: $-50 \mathrm{~cm}$; N4: $-75 \mathrm{~cm}$; N5: $-100 \mathrm{~cm}$ ) applied at day 1. 
has left the profile after 110 days of application.

Figure 12 shows us a solute supply made on the $5^{\text {th }}$ day of simulation. A further peak of $52 \mathrm{mmol} / \mathrm{cm}^{3}$ was observed and the solute remained on the surface until the $32^{\text {nd }}$ day. The $\mathrm{N} 2$ horizon was reached on the $7^{\text {th }}$ day with an approximate peak of $5 \mathrm{mmol} / \mathrm{cm}^{3}$, and was washed out of this horizon on the $48^{\text {th }}$ day. On the $15 \mathrm{~h}$ day the solute reached node $\mathrm{N} 3$ with a peak of $4 \mathrm{mmol} / \mathrm{cm}^{3}$ and then vanished on day 75 . Node N4 was reached on the $24^{\text {th }}$ day with a concentration of $2 \mathrm{mmol} / \mathrm{cm}^{3}$ and was canceled on the $110^{\text {th }}$ day.

For an application dose made on day 10 Figure 13, the solute front disappears

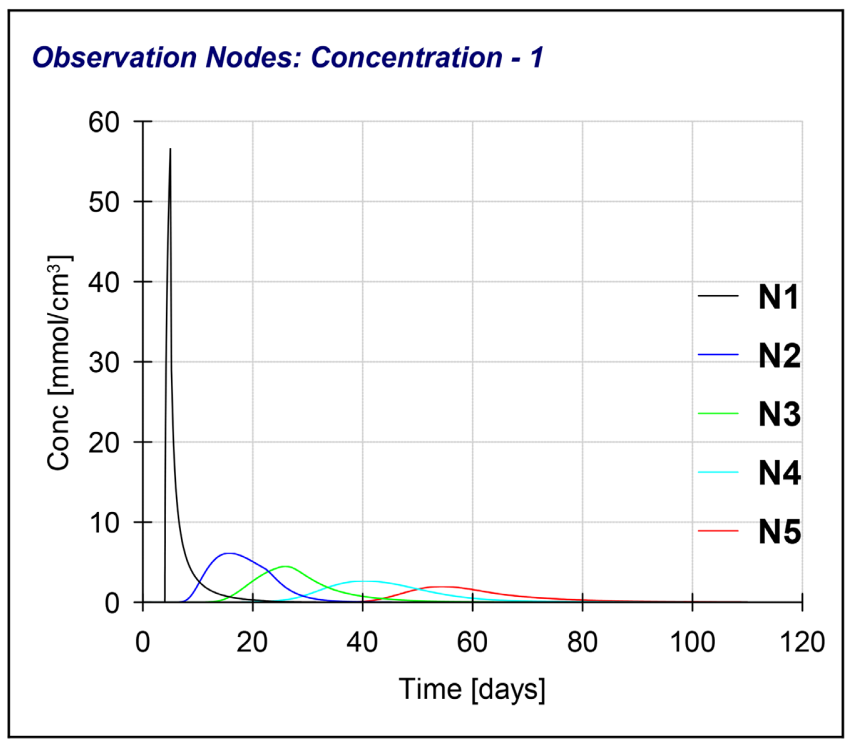

Figure 12. Solute (NPK) concentration versus time at selected observation points (N1: 0 $\mathrm{cm}$; N2: $-20 \mathrm{~cm}$; N3: $-50 \mathrm{~cm}$; N4: $-75 \mathrm{~cm}$; N5: $-100 \mathrm{~cm}$ ) applied at day 5.

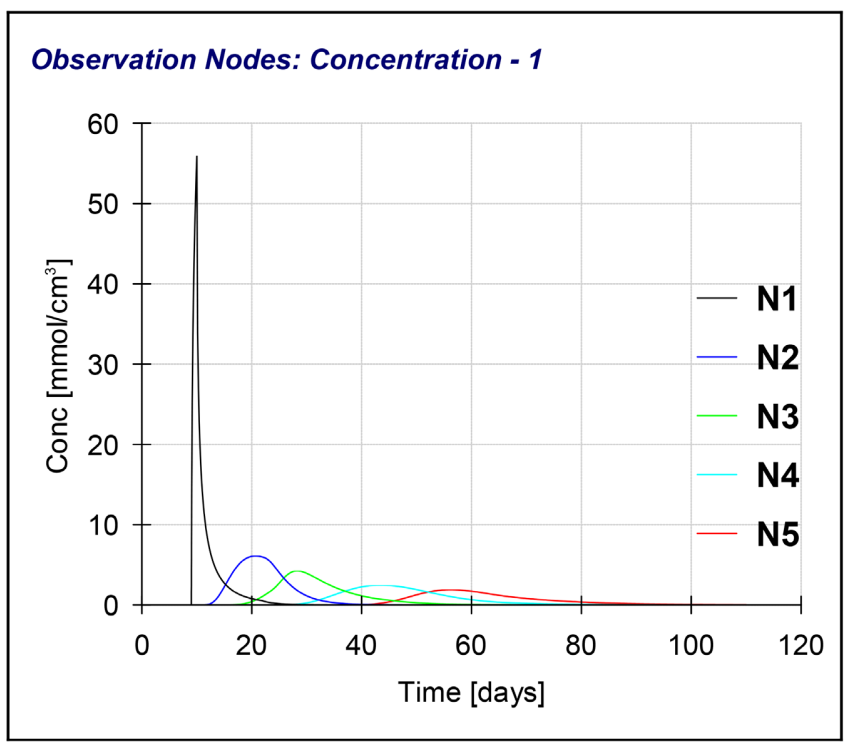

Figure 13. Solute (NPK) concentration versus time at selected observation points (N1: 0 cm; N2: $-20 \mathrm{~cm}$; N3: $-50 \mathrm{~cm}$; N4: $-75 \mathrm{~cm} ; \mathrm{N} 5:-100 \mathrm{~cm}$ ) applied at day 10. 
com pletely from the surface on day 34 . The N2 layer was reached on the $12^{\text {th }}$ day with the same peak of $5 \mathrm{mmol} / \mathrm{cm}^{3}$, this layer then loses the solute on the $50^{\text {th }}$ day. The solute front reached the N3 level on the $19^{\text {th }}$ day with a peak concentration of $4 \mathrm{mmol} / \mathrm{cm}^{3}$. The solute has left this horizon on day 76 , reaching the N4 layer on day 28 and canceling out on day 110 .

Applying a solute dose on day 15 after sowing Figure 14 shows a solute front that persisted at the surface until day 36 . The front continues its distribution to reach level $\mathrm{N} 2$ on the $18^{\text {th }}$ day and remained there until the $52^{\text {nd }}$ day. The N3 layer was then reached on the $25^{\text {th }}$ day, the solute continues its progression to leave the $\mathrm{N} 3$ horizon on the $80^{\text {th }}$ day. The $\mathrm{N} 4$ layer was reached by the $32^{\text {nd }}$ day and the solute finally drains from the horizon on the $110^{\text {th }}$ day.

With a flux corresponding to $75 \% E T_{\text {o }}$ the residence time of the solute on the soil surface decreased as one approaches the date recommended for the application of the solute ( $15^{\text {th }}$ day after sowing). The solute remained on the soil surface $30,28,25,22$ days respectively for a solute applied on the $1^{\text {st }}, 5^{\text {th }}, 10^{\text {th }}$ and $15^{\text {th }}$ day after sowing. It then took an average of 3 days to reach the N2 horizon and 11 days to reach the N3 layer. The concentration of solutes in the different layers decreased with the decrease in the inflow of water. With a lower water flux (compared to that of $100 \% E T_{c}$ ), the solute front distributed more slowly and therefore took longer to reach the other layers (N2, N3, N4 and N5) and would reduce the leaching loss. The solute's stay in the soil was even longer before reaching the bottom limit of the domain.

\subsection{Water Flux $50 \% E T_{c}$ and NPK Applied Either on the $1^{\text {st }} 5^{\text {th, }}$ $10^{\text {th }}$ or $15^{\text {th }}$ Day after Sowing}

For a $50 \% E T_{c}$ treatment, the curve giving the pressure head potential in the soil,

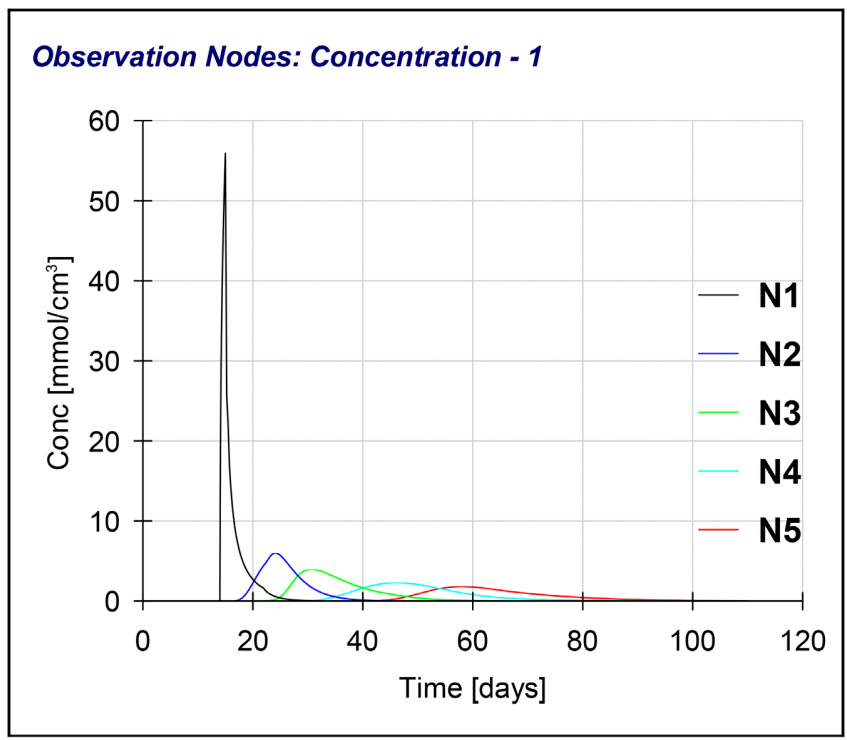

Figure 14. Solute (NPK) concentration versus time at selected observation points (N1: 0 $\mathrm{cm}$; N2: $-20 \mathrm{~cm}$; N3: $-50 \mathrm{~cm}$; N4: $-75 \mathrm{~cm}$; N5: $-100 \mathrm{~cm}$ ) applied at day 15. 
showed an equilibrium-state of the water in the soil from the $70^{\text {th }}$ day until the end of the simulation. The pressure head potential being constant in all observation nodes. Referring to the water mass balance, it can be seen that there was no more water loss in the soil profile after the $66^{\text {th }}$ day but rather water storage in the soil profile.

For a supply of solutes on the $1^{\text {st }}$ day of the simulation Figure 15 the solute spent approximately 49 days on the soil surface (node N1) with a peak concentration of $37.5 \mathrm{mmol} / \mathrm{cm}^{3}$ before disappearing. It then arrived at node $\mathrm{N} 2$ on day 9 to stay there for 86 days before leaving horizon N2; the maximum concentration for $\mathrm{N} 2$ being $2.5 \mathrm{mmol} / \mathrm{cm}^{3}$. Node N3 was reached on the $22^{\text {nd }}$ day, at this level, the solute has left horizon $\mathrm{N} 3$ on the $110^{\text {th }}$ day of the simulation. On the $35^{\text {th }}$ day, the solute reached node $\mathrm{N} 4$ and leaved this horizon on the $110^{\text {th }}$ day. The bottom of the domain (node N5) was reached on the $59^{\text {th }}$ day, at this layer, the concentration of the solute did not cancel out even after the $110^{\text {th }}$ day.

For an NPK treatment on the $5^{\text {th }}$ day after sowing Figure 16 the solute has spent 50 days on the soil surface (node N1) before dispersing inside the soil. Continuing its progression through the soil, the solute arrived at node N2 on day 12 and canceled out on day 96 . The distribution of the solute being done with the water infiltration, node $\mathrm{N} 3$ was reached on the $25^{\text {th }}$ day; the solute has left the $\mathrm{N} 3$ horizon on the $110^{\text {th }}$ day. 10 days after reaching node N3, the solute has arrived at node $\mathrm{N} 4$ and was no longer washed out of this horizon, even after the $110^{\text {th }}$ day of simulation. Likewise, after reaching node N5 on the $59^{\text {th }}$ day, the solute remained at the bottom of the domain after the $110^{\text {th }}$ day, but at low concentration.

Figure 17 shows us a supply of solutes made on the $10^{\text {th }}$ day, we observed through node N1 that the solute has made 52 days at the surface of the soil with

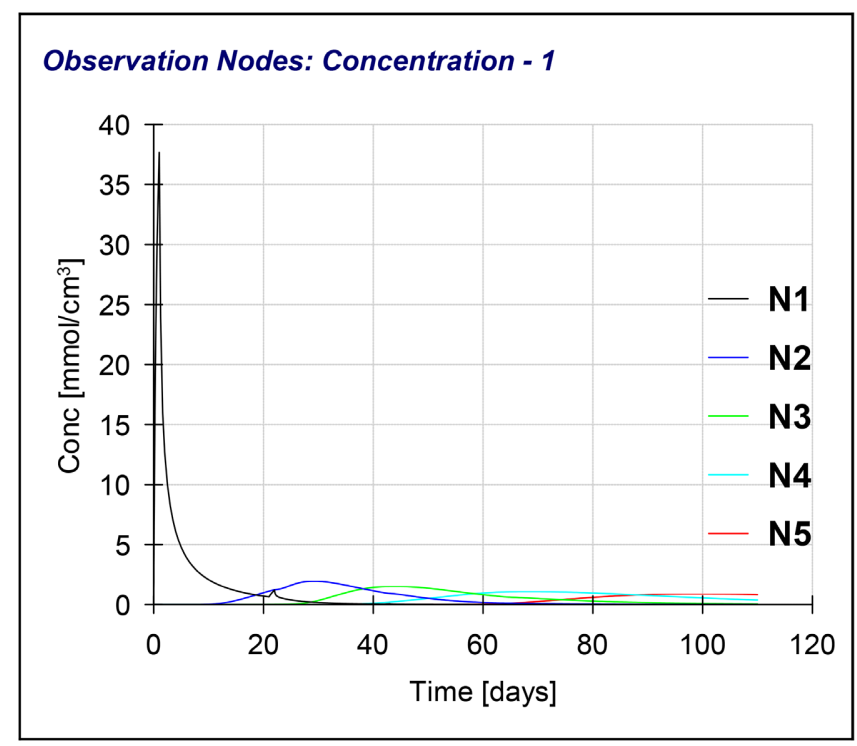

Figure 15. Solute (NPK) concentration versus time at selected observation points (N1: 0 $\mathrm{cm} ; \mathrm{N} 2:-20 \mathrm{~cm} ; \mathrm{N} 3:-50 \mathrm{~cm} ; \mathrm{N} 4:-75 \mathrm{~cm}$; N5: $-100 \mathrm{~cm}$ ) applied at day 1. 


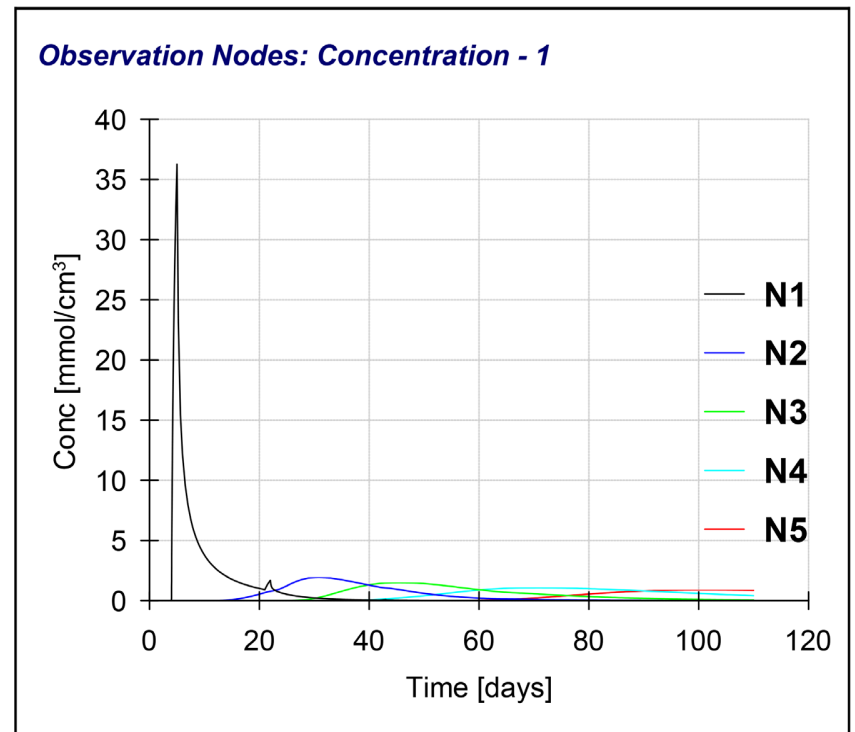

Figure 16. Solute (NPK) concentration versus time at selected observation points (N1: 0 $\mathrm{cm} ; \mathrm{N} 2:-20 \mathrm{~cm}$; N3: $-50 \mathrm{~cm}$; N4: $-75 \mathrm{~cm}$; N : $-100 \mathrm{~cm}$ ) applied at day 5 .

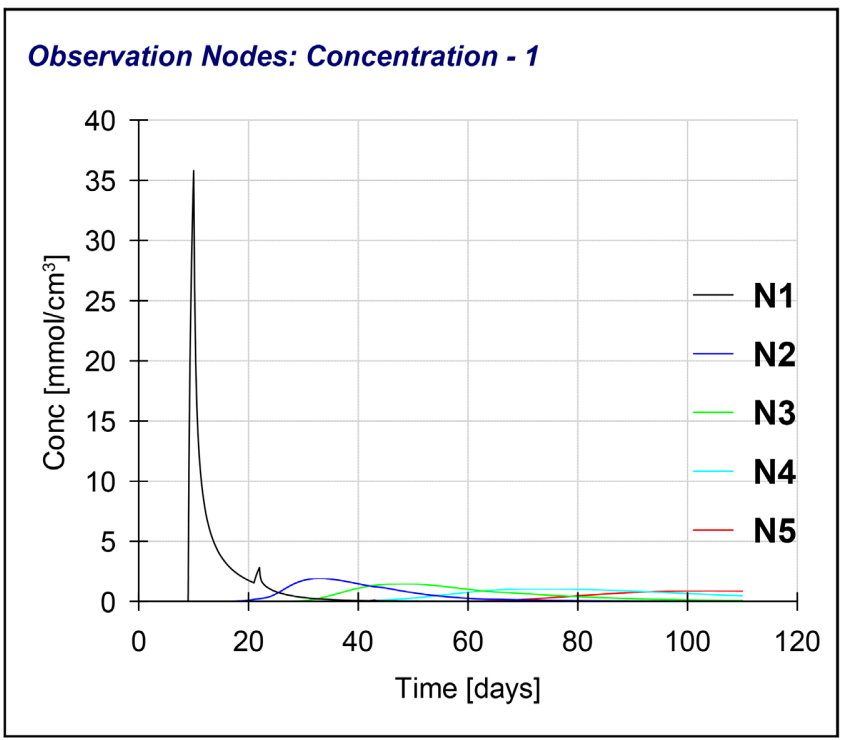

Figure 17. Solute (NPK) concentration versus time at selected observation points (N1: 0 $\mathrm{cm}$; N2: $-20 \mathrm{~cm}$; N3: $-50 \mathrm{~cm}$; N4: $-75 \mathrm{~cm}$; N : $-100 \mathrm{~cm}$ ) applied at day 10.

a peak concentration of $36 \mathrm{mmol} / \mathrm{cm}^{3}$. Horizon $\mathrm{N} 2$ was reached on the $18^{\text {th }}$ day, the solute left this horizon on the $98^{\text {th }}$ day of simulation. Continuing its progression inside the ground, the solute arrived at node N3 on the $28^{\text {th }}$ day and was washed away from this horizon on the $110^{\text {th }}$ day. The two nodes N4 and N5 were reached by the solute respectively on the $38^{\text {th }}$ and $62^{\text {nd }}$ day. At these last two nodes, the solute was no longer leached even after the last day of simulation. But concentrations remained low at these horizons.

Applying a dose of solute on day 15 Figure 18, the solute remained on the soil surface until the $54^{\text {th }}$ day. The solute front has continued its distribution to reach 


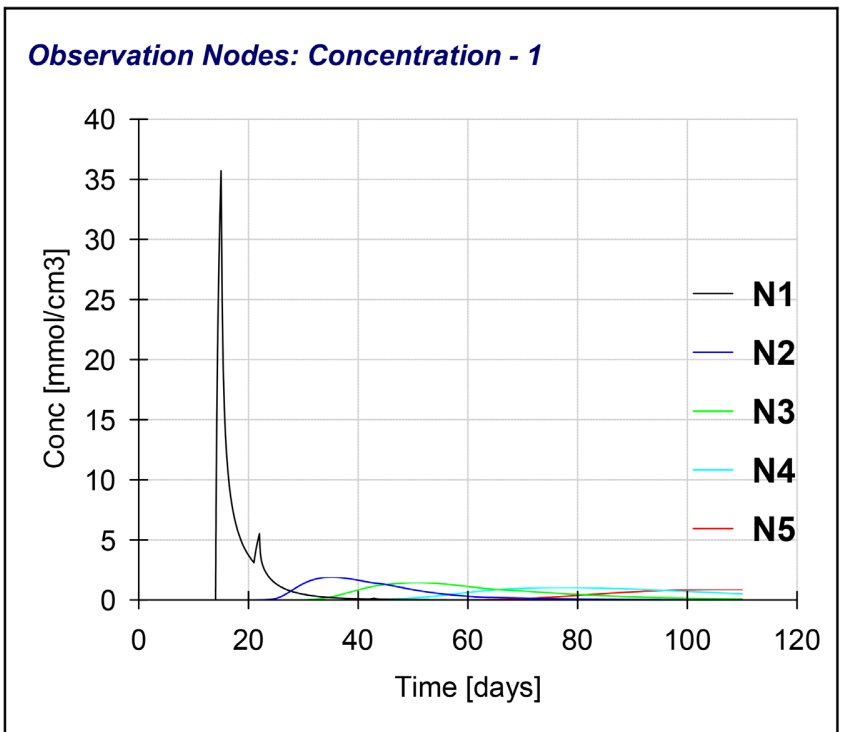

Figure 18. Solute (NPK) concentration versus time at selected observation points (N1: 0 cm; N2: $-20 \mathrm{~cm}$; N3: $-50 \mathrm{~cm}$; N4: $-75 \mathrm{~cm}$; N5: $-100 \mathrm{~cm}$ ) applied at day 15.

node $\mathrm{N} 2$ on the $24^{\text {th }}$ day and left this horizon on the $102^{\text {nd }}$ day. Then, the solute reached the observation node $\mathrm{N} 3$ on the $31^{\text {st }}$ day of simulation and was washed out of this horizon on the $110^{\text {th }}$ day. Nodes N4 and N5 were crossed respectively on the $40^{\text {th }}$ and $62^{\text {nd }}$ days of simulations. The solute's concentration on those nodes was no longer vanished indicating that the solute remains present at the bottom of the domain, even after the simulation has ended.

With a $50 \% E T_{c}$ treatment, the time that the solute did on the soil surface decreases as one approaches the recommended day for the application of the solute ( $15^{\text {th }}$ day after sowing). The same observation was made for the flows corresponding to $100 \% E T_{\mathcal{o}}$ and $75 \% E T_{c}$. The solute remained on the surface of the soil $49,46,43,40$ days respectively for a solute applied on the $1^{\text {st }}, 5^{\text {th }}, 10^{\text {th }}$ and $15^{\text {th }}$ day after sowing. It then took an average of 8 days to reach the $\mathrm{N} 2$ horizon and 19 days to reach the N3 layer. The concentration of solutes in the different layers decreased with the decrease in the inflow of water. With a lower water flow (compared to that of $75 \% E T_{\circ}$ or $100 \% E T_{c}$ ), the solute front distributed more slowly and therefore took longer to reach the other horizons (N2, N3, N4 and $\mathrm{N} 5$ ) and reduced leaching loss. With $50 \% E T_{\mathcal{O}}$ the residence time of the solute on the surface was significantly longer. No solute was lost at the bottom edge of the domain for the various treatments on the last day of simulations.

The first two layers of the soil being sandy, this explains the fairly rapid leaching towards the last layer for high water flux $\left(100 \% E T_{\mathcal{\circ}}\right.$ and $\left.75 \% E T_{c}\right)$. Only the $50 \% E T_{c}$ treatment made it possible to gain water and solutes (no deep drainage or leaching beyond the limit of the bottom of the domain). An addition of solute on the $1^{\text {st }}$ or $5^{\text {th }}$ day after sowing regardless of the water flux provided (100\% $E T_{\odot}, 75 \% E T_{\odot}$ or $50 \% E T_{c}$ ) will not have a great impact on the absorption of solute by the crop because the roots are not yet developed at this stage. We 
analyzed the solute inputs on the $10^{\text {th }}$ and $15^{\text {th }}$ day after sowing. The closer we got to the $15^{\text {th }}$ day, the more we have got a loss of solutes, probably due to the gradual storage of water, as it adds up. A favorable day for solute supply would therefore be between the $10^{\text {th }}$ and $14^{\text {th }}$ day after sowing. To reduce the solute infiltration velocity into the soil layers, one could inject solute without first supplying water the day before or the day after application. By simulating such a process, we realized that this treatment in addition to reducing the solute infiltration rate in the soil, also increases the concentration of the solute in the different horizons of the soil. This would increase the availability of the solute for the roots of the crop.

\section{Conclusion}

We simulated water and non-reactive solutes' transport into a 3-layered soil profile, with the Hydrus 1D software. For the simulation, we evaluated the doses of solutes that should be provided for the production of the intermediate variety of maize, the crop cycle of which was estimated at 110 days over an area of $500 \mathrm{~m}^{2}$. Different simulations were performed at $100 \% E T_{\odot}, 75 \% E T_{\mathcal{c}}$ and $50 \% E T_{c}$ in terms of water supplies combined at the doses of $100 \mathrm{mmol} / \mathrm{L} / \mathrm{m}^{2} \mathrm{NPK}$ and 246 $\mathrm{mmol} / \mathrm{L} / \mathrm{m}^{2}$ of urea for the solute inputs, referring to the technical itinerary for maize production in Burkina Faso. For the three simulated treatments, there was more deep drainage for water flux at $100 \% E T_{c}$ or $75 \% E T_{o}$ leading at the same time to loss of solutes beyond a certain depth of the soil not colonized by roots. The water flux at $50 \% E T_{c}$ further reduced the loss of water by drainage and of solutes by leaching, this flux hardly caused any loss beyond the bottom of the domain. It has also improved the residence time of solute in the soil. The closer one gets to the $15^{\text {th }}$ day after sowing, the greater the risk of loss, because the soil has already absorbed water. This loss can be reduced by spacing the water supply and the solute supply, or by amending soil with organic matter in order to increase its retention capacity, which could improve the residence time of the solute.

\section{Acknowledgements}

The authors would like to thank Ouédraogo T. Stephane for reading and correcting the paper.

\section{Conflicts of Interest}

The authors declare no conflicts of interest regarding the publication of this paper.

\section{References}

[1] Zhu, Z.L. and Chen, D.L. (2002) Nitrogen Fertilizer Use in China-Contributions to Food Production, Impacts on the Environment and Best Management Strategies. Nutrient Cycling in Agroecosystems, 63, 117-127. https://doi.org/10.1023/A:1021107026067

[2] Sansoulet, J. (2007) Transfert d'eau et des ions potassium et nitrate dans un sol à 
capacité d'échange anionique sous un couvert redistributeur de la pluie: Etude expérimentale et modélisation dans une bananeraie fertilisée sur un andosol. Thèse de Doctorat, Institut National Agronomique Paris Grignon, Paris.

[3] Siyal, A.A., Bristow, K.L. and Simunek, J. (2012) Minimizing Nitrogen Leaching from Furrow Irrigation through Novel Fertilizer Placement and Soil Surface Management Strategies. Agricultural Water Management, 115, 242-251.

https://doi.org/10.1016/j.agwat.2012.09.008

[4] Cabioche, Y.M., Clermont-Dauphin, C., Lafont, A., Sansoulet, J., Cattan, P., Achard, R., Caron, A. and Charbier, C. (2006) Stockage dans les sols à charges variables et dissipation dans les eaux de zoocides organochlorés autrefois appliqués en bananeraies aux Antilles: Relation avec les systèmes de culture. Rapport final de contrat de recherche, AP "Pesticides" 2002 MEDD. APC INRA Antilles-Guyane.

[5] Pereira, L.S., Cordery, I. and Iacovides, I. (2012) Improved Indicators of Water Use Performance and Productivity for Sustainable Water Conservation and Saving. Agricultural Water Management, 108, 39-51. https://doi.org/10.1016/j.agwat.2011.08.022

[6] Bar-Yosef, B. (1999) Advances in Fertigation. Advances in Agronomy, 65, 1-77. https://doi.org/10.1016/S0065-2113(08)60910-4

[7] Cote, C.M., Bristow, K.L., Charlesworth, P.B., Cook, F.J. and Thorburn, P.J. (2003) Analysis of Soil Wetting and Solute Transport in Subsurface Trickle Irrigation. Irrigation Science, 22, 143-156. https://doi.org/10.1007/s00271-003-0080-8

[8] Gärdenäs, A.I., Hopmans, J.W., Hanson, B.R. and Simunek, J. (2005) Two Dimensional Modeling of Nitrate Leaching for Various Fertigation Scenarios under Micro-Irrigation. Agricultural Water Management, 74, 219-242.

https://doi.org/10.1016/j.agwat.2004.11.011

[9] Rajput, T.B.S. and Patel, N. (2006) Water and Nitrate Movement in Drip-Irrigated Onionunder Fertigation and Irrigation Treatments. Agricultural Water Management, 79, 293-311. https://doi.org/10.1016/j.agwat.2005.03.009

[10] Ajdary, K., Singh, D.K., Singh, A.K. and Khanna, M. (2007) Modelling of Nitrogen Leaching from Experimental Onion Field under Drip Fertigation. Agricultural Water Management, 89, 15-28. https://doi.org/10.1016/j.agwat.2006.12.014

[11] Doltra, J. and Munoz, P. (2010) Simulation of Nitrogen Leaching from a Fertigated Crop Rotation in a Mediterranean Climate Using the EU-Rotate_N and Hydrus-2D Models. Agricultural Water Management, 97, 277-285. https://doi.org/10.1016/j.agwat.2009.09.019

[12] Hussein, F., Janat, M. and Yakoub, A. (2011) Assessment of Yield and Water Use Efficiency of Drip-Irrigated Cotton (Gossypium hirsutum L.) as Affected by Deficit Irrigation. Turkish Journal of Agriculture and Forestry, 35, 611-621.

[13] Ityel, E., Lazarovitch, N., Silberbush, M. and Ben-Gal, A. (2011) An Artificial Capillary Barrier to Improve Root Zone Conditions for Horticultural Crops: Physical Effects on Water Content. Irrigation Science, 29, 171-180. https://doi.org/10.1007/s00271-010-0227-3

[14] Badr, A.E. and Abuarab, M.E. (2013) Soil Moisture Distribution Patterns under Surface and Subsurface Drip Irrigation Systems in Sandy Soil Using Neutron Scattering Technique. Irrigation Science, 31,317-332. https://doi.org/10.1007/s00271-011-0306-0

[15] Kandelous, M.M., Kamai, T., Vrugt, J.A., Šimunek, J., Hanson, B. and Hopmans, W. (2012) Evaluation of Subsurface Drip Irrigation Design and Management Parame- 
ters for Alfalfa. Agricultural Water Management, 109, 81-93. https://doi.org/10.1016/j.agwat.2012.02.009

[16] Pang, X.P. and Letey, J. (1998) Development and Evaluation of ENVIRO-GRO, an Integrated Water, Salinity, and Nitrogen Model. Soil Science Society of America Journal, 62, 1418-1427. https://doi.org/10.2136/sssaj1998.03615995006200050039x

[17] Li, R., Ma, J. and Zhang, R. (2003) Estimating Nitrate Leaching with a Transfer Function Model Incorporating Net Mineralization and Uptake of Nitrogen. Journal of Environmental Quality, 32, 1455-1463. https://doi.org/10.2134/jeq2003.1455

[18] Phogat, V., Skewes, M.A., Cox, J.W., Sanderson, G., Alam, J. and Simunek, J. (2014) Seasonal Simulation of Water, Salinity and Nitrate Dynamics under Dripirrigated Mandarin (Citrus reticulata) and Assessing Management Optionsfor Drainage and Nitrate Leaching. Journal of Hydrology, 513, 504-516.

https://doi.org/10.1016/j.jhydrol.2014.04.008

[19] Skaggs, T.H., Trout, T.J., Šimunek, J. and Shouse, P.J. (2004) Comparison of Hydrus-2D Simulations of Drip Irrigation with Experimental Observations. Journal of Irrigation and Drainage Engineering, 130, 304-310. https://doi.org/10.1061/(ASCE)0733-9437(2004)130:4(304)

[20] Lazarovitch, N., Pollton, M., Furman, A. and Warrick, A.W. (2009) Water Distribution under Trickle Irrigation Predicted Using Artificial Neural Networks. Journal of Engineering Mathematics, 64, 207-218. https://doi.org/10.1007/s10665-009-9282-2

[21] Abou Lila, T.S., Berndtsson, R., Persson, M., Somaida, M., Ei-Kiki, M., Hamed, Y. and Mirdan, A. (2013) Numerical Evaluation of Subsurface Trickle Irrigation with Brackish Water. Irrigation Science, 31, 1125-1137.

https://doi.org/10.1007/s00271-012-0393-6

[22] Dabach, S., Lazarovitch, N., Simunek, J. and Shai, U. (2013) Numerical Investigation of Irrigation Scheduling Based on Soil Water Status. Irrigation Science, 31, 27-36. https://doi.org/10.1007/s00271-011-0289-x

[23] Ramos, T.B., Simunek, J., Gonçalves, M.C., Martins, J.C., Prazeres, A. and Pereira, L.S. (2012) Two-Dimensional Modeling of Water and Nitrogen Fate from Sweet Sorghum Irrigated with Fresh and Blended Saline Waters. Agricultural Water Management, 111, 87-104. https://doi.org/10.1016/j.agwat.2012.05.007

[24] Bof Bufon, V., Lascano, R.J., Bednarz, C., Booker, J.D. and Gitz, D.C. (2012) Soil Water Content on Drip Irrigated Cotton: Comparison of Measured and Simulated Values Obtained with the Hydrus-2D Model. Irrigation Science, 30, 259-273. https://doi.org/10.1007/s00271-011-0279-z

[25] Sanou, J. (2004) Grille variétale de maïs vulgarisé et fertilisation minérale recommandée au Burkina Faso. Département de Productions Végétaeles, INERA.

[26] Kebre, M.B. (2013) Gestion des Ressources en Eau dans les Régions Arides: Analyse Expérimentale d'un Sol Type du Burkina Faso et Modélisation Numérique des Transferts d'Eau. Thèse de doctorat, Civil Engineering, Université Montpellier II-Sciences et Techniques du Languedoc, Montpellier.

[27] Simunek, J., Sejna, M., Saito, H., Sakai, M. and van Genuchten, M.T. (2013) The HYDRUS-1D Software Package for Simulating the Onedimensional Movement of Water, Heat, and Multiple Solutes in Variably-Saturated Media: Version 4.16. Department of Environmental Sciences, University of California, University of California, Riverside.

[28] van Genuchten, M.T. (1980) A Closed Form Equation for Predicting the Hydraulic Conductivity of Unsaturated Soils. Soil Science Society of America Journal, 44, 892-898. https://doi.org/10.2136/sssaj1980.03615995004400050002x 